\section{Physico-Chemical Characteristics and Storage Stability of Breadfruit and Cassava Co-Fermented into Gari Analogue}

\section{Abstract}

This study concentrated majorly on producing a functional food; gari analogue from co-fermented breadfruit and cassava. A portion of both mature cassava tubers and matured but unripe breadfruit (Artocarpus altilis) was co-fermented (100:0, 0:100, 80:20, 70:30, and 60:40 Cassava: Breadfruit) to obtain gari analogue. The physico-chemical characteristics ( $\mathrm{pH}$, titratble acidity and cyanide content) of the fermenting mash were examined daily till the end of the fermentation days, also on the final gari analogue after production. The final gari analogue were stored in a plastic covered containers for six weeks during which $\mathrm{pH}$, titratable acidity and cyanide evaluation were conducted weekly to determine if there could be any appreciable changes in acidity and taste of gari analogue samples. The $\mathrm{pH}$ of the samples decreased with increase in process time of the fermenting mash, breadfruits samples had lower $\mathrm{pH}$ than those cassava samples. Titratable acidity increased with increase in fermenting days as all samples had higher acid content at the end of fermentation period comparable with the initial acid content while the co-fermented gari samples had lower cyanogenic glycosides than $100 \%$ cassava gari. This study established that co-fermentation of breadfruit and cassava into analogue reduced the cyanogenic glycosides of gari with increase in titratable acidity (TTA) and decrease in $\mathrm{pH}$ values which in turn played a major role in altering the taste of the final gari analogue and its storage stability.

Keywords: Breadfruit; Cassava; Physico-chemical; Titratable acidity; Cyanide

\author{
Ajifolokun OM* \\ Department of Food Science and \\ Technology, Obafemi Awolowo University, \\ Ile-Ife, Osun-State, Nigeria
}

\section{*Corresponding author: Ajifolokun OM \\ ” maryoluyinka2@gmail.com \\ Department of Food Science and Technology, Obafemi Awolowo University, Ile-Ife, Osun-State, Nigeria.}

Tel: $+27732265948 /+2348137251859$

Citation: Ajifolokun OM (2018) PhysicoChemical Characteristics and Storage Stability of Breadfruit and Cassava CoFermented into Gari Analogue. J Food Nutr Popul Health Vol.2 No.1:4

Received: February 26, 2018; Accepted: March 22, 2018; Published: March 26, 2018

\section{Introduction}

Cassava (Manihot esculenta) is widely cultivated and consumed in tropical countries of Asia, South America and Africa where it is a staple food for many people (Cock, 1985). Cassava contains more than one form of cyanogenic glucosides, its uses as human food are limited by its perishability, low protein content and potential toxicity when not properly fermented. In West Africa, cassava is popularly eaten in fermented forms such as gari, lafun, fufu and starch [1-4]

Different varieties of cassava are generally classified into two main types: sweet cassava and bitter cassava. Sweet cassava roots contain less than $50 \mathrm{mg}$ per $\mathrm{kg}$ hydrogen cyanide on fresh weight basis, whereas that of the bitter variety contains up to $400 \mathrm{mg}$ per kg. Cassava roots can generally be made safe to eat by peeling and thorough cooking. However, bitter cassava roots require extensive processing. One of the traditional processes to prepare bitter cassava roots is through peeling, grating and fermentation which precede cooking in order to release the volatile hydrogen cyanide gas. Another process of preparing bitter cassava roots is through cutting, soaking and boiling in water; and this is particularly effective in reducing the cyanide content in cassava roots. Hence, adequately processed cassava based products with very low cyanide contents are considered safe to use by humans and for livestock feeds [5-24].

One of the most important staple foods in Nigeria is gari which is obtained from cassava. Gari is creamy white, granular flour with a slightly fermented flavour and sour taste. It is made from freshly harvested cassava tubers which are cleaned, grated, dewatered, left to ferment and then roasted. It is a staple food in many communities in West Africa [6]. Gari is by far the most popular form in which cassava is consumed in Nigeria and other West African countries [17]. 
However, it is very poor in nutrients especially protein $(0.7$ to $1.2 \%)$. Prolonged consumption of gari without adequate protein and other vitamins supplements will eventually lead to malnutrition. Therefore, providing cassava - based diets with supplemental high quality protein for adults and growing children may be necessary. One way this could be accomplished is by blending gari with breadfruit, which is relatively high in protein.

Gari is utilized in various ways and its consumption is on the increase due to the convenience of its preparation into several forms. The inclusion of certain percentage of cassava flour or starch in wheat flour and the utilization of cassava in biofuel production has increased the utilization of cassava and consequently affected the price of cassava products including gari.

Breadfruit (Artocarpus altilis), the seedless variety is a fruit producing plant which is native to Polynesia. The plant belongs to the Moraceae family of about 50 genera and over 1000 species. Breadfruit is propagated through stem-cuttings and the average first fruiting period of the crop is between 4 to 6 years [9]. It produces its fruits up to three times in a year and the number of fruits produced is very high. The fruit has been described as an important staple food of a high economic value. Although many people have heard of breadfruit, few have eaten it, hence, breadfruit is one of the underutilized fruits and it differs from other fruits because it has to be cooked before consumption.

Breadfruit is highly nutritious, cheap and readily available but is currently underutilized both at household and industrial level because of the way it is perceived by the society and its high perishability. Therefore, the co-fermentation of breadfruit with cassava into gari analogue with comparable physico-chemical and sensory qualities comparable to gari with low microbial load will increase the utilization of breadfruit as an analogue to cassava in gari processing hence the objectives of this study.

\section{Materials and Methods}

Freshly harvested matured but unripe breadfruits and matured cassava tubers were purchased at Ita-Osa market, lle-Ife, OsunState, Nigeria. Microbiological media and chemicals of analytical grade were procured from reputable scientific supplies store in Ile-Ife, Nigeria. Equipments were supplied by the Department of Food Science and Technology and Central Science laboratory, Obafemi Awolowo University, Ile-Ife, Nigeria.

\section{Fermentation of breadfruit to gari}

Matured green ripe breadfruits were weighed, washed, peeled and decored manually. Afterwards they were sliced manually into $1 \mathrm{~cm}$ thick slices. The slices were grated mechanically and the mash obtained was put in a bag and subjected to hydraulic press for 5 days $(72 \mathrm{~h}$ ) during which fermentation occurred and the juice drained off. The dried cake was then sieved and roasted in a metal pan over wood fire. The product obtained i.e., gari and gari analogue were packaged in polythene bags for further analysis. The flow chart for the production of breadfruit gari is shown in Figure 1 [11].

\section{Fermentation of cassava to gari}

Cassava tubers were sorted manually to separate roots, leaves and debris; they were weighed and then peeled manually. The peeled tubers were thoroughly washed and grated with a mechanical grater. The mash obtained was put in a bag and subjected to heavy pressure for five days during which fermentation occurred and the juice was drained off. The gari produced was covered with plastic container for further analysis. The flow chart for the production of cassava meal is shown in Figure 2 [5].

\section{Co-fermentation of breadfruit and cassava into gari analogue}

Three blends were prepared by weighing and mixing breadfruit mash and cassava mash in the following proportion of $80: 20$, 70:30 and 60:40. Others were $100 \%$ Cassava (control) and $100 \%$

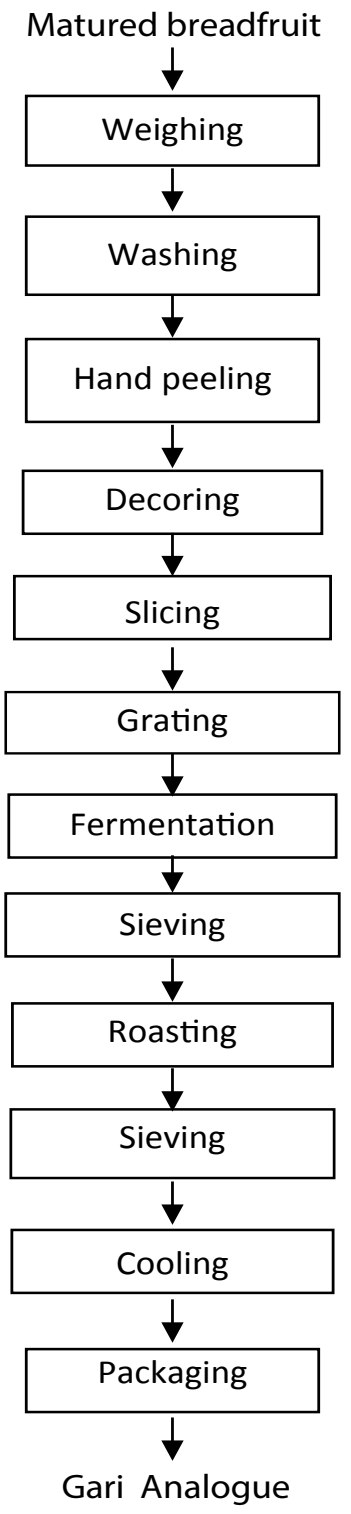

Figure 1 Process flow of gari analogue from breadfruit [11]. 


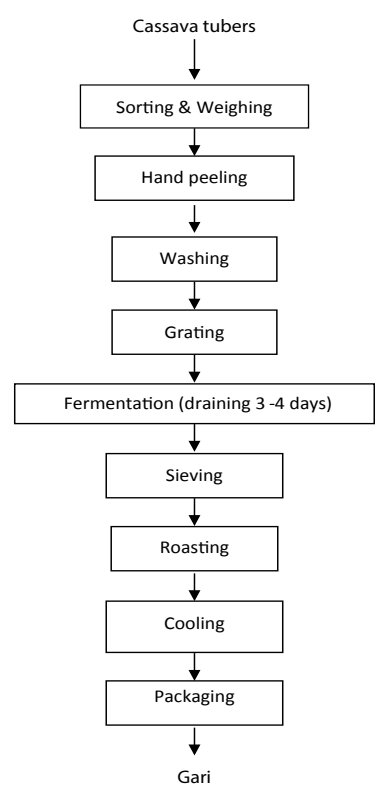

Figure 2 Process flowof gari from cassava tubers $[5,14]$.

Breadfruit. As shown in Figure 3. Each of the blends obtained and the controls of the experiment were made to undergo microbiological, physical, chemical and sensory analyses.

\section{Determination of $\mathrm{pH}$}

$\mathrm{pH}$ or hydrogen ion concentration of each sample was measured with a standard meter (ATC, model HI-8915). The $\mathrm{pH}$ meter was standardized with standard buffers of $\mathrm{pH} 4$ and $\mathrm{pH}$ 7. $\mathrm{pH}$ was determined by making a $10 \% \mathrm{w} / \mathrm{v}$ suspension of the sample in distilled water. The suspension was mixed thoroughly and the probe of the $\mathrm{pH}$ meter that had been subjected to calibration with buffer 7 was introduced into each. Readings were taken when the readings were stable [10].

\section{Determination of titratable acidity}

Titratable acidity (expressed as lactic acid) was determined using the method [13]. Homogenate of the sample was prepared like that of $\mathrm{pH}$ determination. The slurry was filtered through Whatman No 1 filter paper. Aliquot $(10 \mathrm{~mL})$ was titrated with 0.1 $\mathrm{M} \mathrm{NaOH}$ using phenolphtalene as the end point indicator. Three drops of $0.1 \%$ phenolphtalene indicator was added to flask and was mixed thoroughly before titration with $0.1 \mathrm{M} \mathrm{NaOH}$. Titration was continued until a permanent pink color was observed. In each case, titratable acidity was expressed as lactic acid as follows; 1 $\mathrm{mL}$ of $0.1 \mathrm{M} \mathrm{NaOH}=0.009 \mathrm{~g}$ of lactic acid

\section{Determination of cyanide content}

Hydrogen cyanide content of gari was determined according to a procedure of Rosling [23]. Ten grams of each sample was put into a kjeldahl bottle and into each was added $10 \mathrm{~mL}$ of distilled water. This was incubated at room temperature for $2 \mathrm{~h}$. Thereafter, 100 $\mathrm{mL}$ of distilled water was added and the samples were distilled. Exactly $130 \mathrm{ml}$ of the distillate wad added in an Erlenmeyer flask and was filled with $20 \mathrm{~mL}$ of $2.5 \% \mathrm{NaOH}$. Thereafter, $8 \mathrm{ml}$ of $\mathrm{NH}_{4} \mathrm{OH}$ and $5 \mathrm{~mL}$ of $5 \% \mathrm{KI}$ were added. Finally, the distillate was titrated against $0.02 \mathrm{~N} \mathrm{AgNO}_{3}$ until the color changed indicating the titre point. $\mathrm{HCN}$ content was calculated using the equation:

\section{Storage of gari and gari analoque}

All the gari samples were stored at ambient temperature in an air tight container for a period of six weeks. On a weekly basis, the $\mathrm{pH}$ and TTA were determined using the methods described above. Total viable count, yeast and mould count and lactic acid bacteria counts were also determined using the methods $[15,16]$.

\section{Results and Discussion}

\section{$\mathrm{pH}$ of sample}

Results of $\mathrm{pH}$ readings of all the samples during fermentation are presented in Figure 4. The $\mathrm{pH}$ of all the samples decreased with increase in process time of the fermenting mash although breadfruit had $\mathrm{pH}$ values that were lower than those of cassava. One hundred percent cassava gari has the lowest decrease in $\mathrm{pH}$ value of 5.90 on the initial day to 3.69 on the final day, this is a difference of 2.21 while $70: 30 \%$ gari mash decreased from 6.91 on day zero to 3.68 on the fifth day, with a difference of 3.29. This is as a result of production of organic acid during fermentation which was responsible for the sour taste, a unique characteristics of gari [8]. The more the acid produced the lower the value of the $\mathrm{pH}$. Apart from this, $\mathrm{pH}$ changes during this study followed the typical pattern [20] for gari fermentation, where there is a rapid drop of $\mathrm{pH}$ within the first $24 \mathrm{~h}$ followed by very minimal changes up to the end of fermentation.

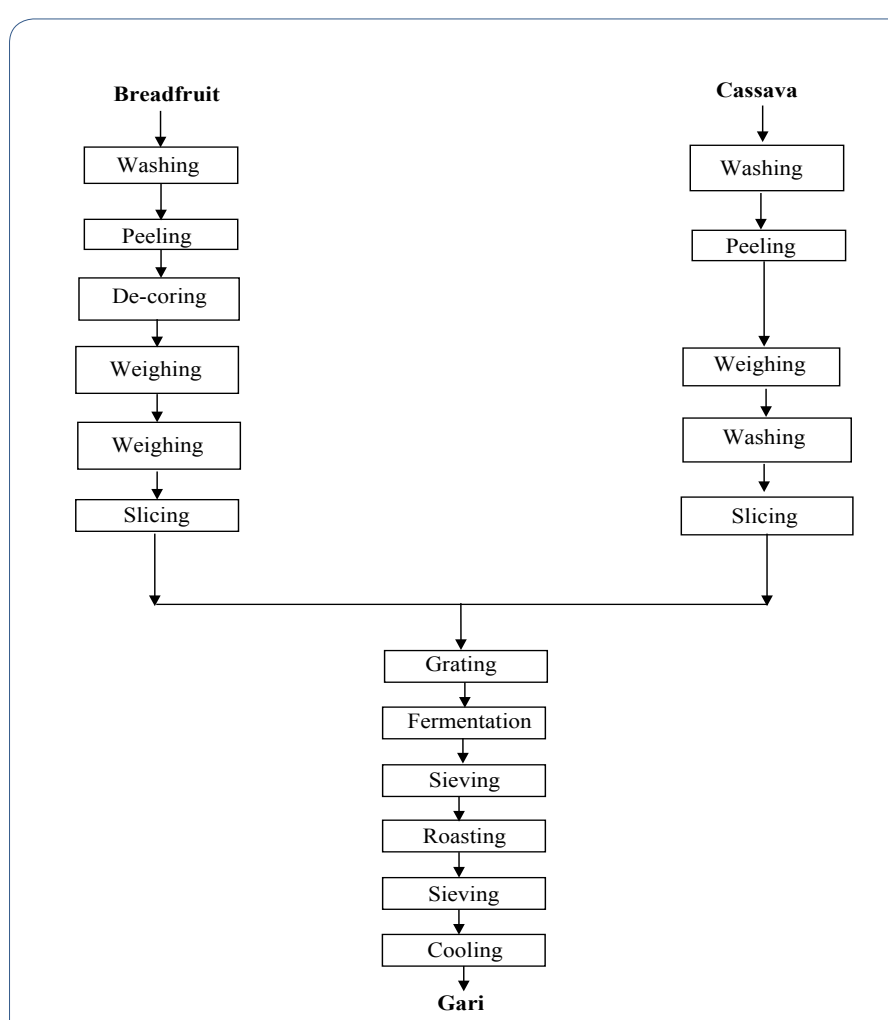

Figure 3 Process flow for the co- processing of breadfruit and cassava tuber into gari. 


\section{Titratable acidity of samples}

The titratable acidity of all the samples during fermentation ranged between 0.0016 and $0.0061 \mathrm{mg} / \mathrm{g}$ lactic acid. It was observed that the acidity increased with increase in the number of fermentation time. Titratable acidity of $100 \%$ cassava gari increased from $0.0018-0.0061$ (mg/g) lactic acid. All samples were observed to have higher acid content at the end of the fermentation period as compared with the initial acid content. Production of organic acids by LAB on starch substrates could be responsible for the decrease in $\mathrm{pH}$ and increase in TTA [19]. Increase in acidity could play a role in the preservation of the fermented products and could also alter the taste of the final gari products [3].

\section{Cyanide content of samples during fermentation}

Figure 5 shows the result of cyanogenic glucosides of gari samples. The $100 \%$ cassava gari has the highest content of cyanogenic glucosides of $13.72 \mathrm{mg} / \mathrm{HCN} / \mathrm{Kg}$ while $100 \%$ breadfruit gari has the lowest content of $8.1 \mathrm{mg} / \mathrm{HCN} / \mathrm{Kg}$. The co-fermented gari samples had lower cyanogenic glucosides than $100 \%$ cassava gari. The presence of breadfruit has really reduced the cyanogenic glycosides of gari. The cyanide content of all the samples are within the same range with the data earlier reported for some cassava products of $(10.5 \mathrm{mg} / \mathrm{HCN} / \mathrm{Kg}[4,21,22]$. Moreover, the cyanide levels are far below the detrimental level of $30 \mathrm{mg} / \mathrm{kg}$ [6]. These products could therefore be considered safe with regard to cyanide poisoning. Co-fermentation of cassava and breadfruit in production of gari analogue is an effective way of obtaining gari products of extremely low level of Hydrogen cyanide.

When plant tissues are crushed (mashed roots), the plant cell structure may be so damaged that the enzymes can meet with and

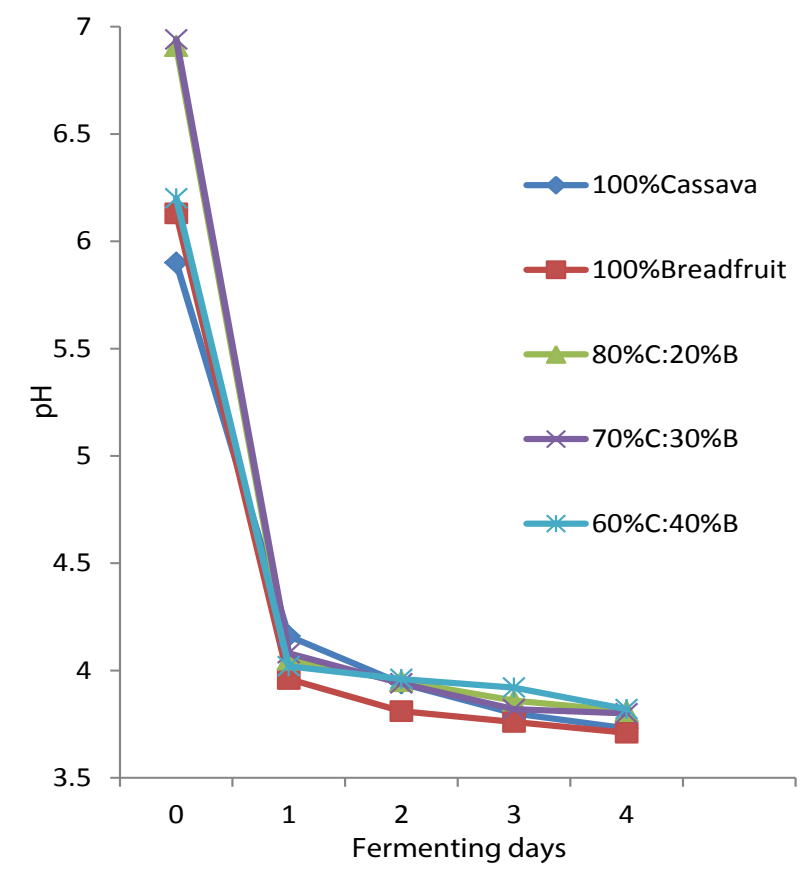

Figure $4 \mathrm{pH}$ of the co-fermented cassava and breadfruit meal during fermentation.

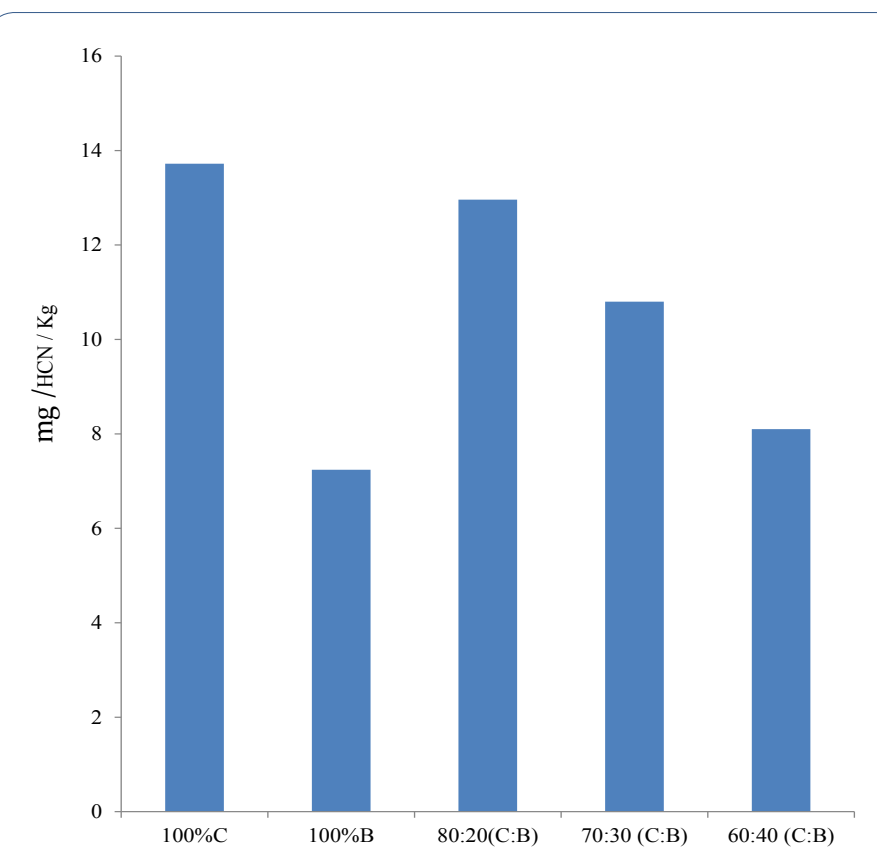

Figure 5 Cyanide content of gari and gari analogue samples.

act on the cyanogenic glycoside [12]. The action of linamarase on Linamarin and Lotaustralin are the hydrolytic release of acetone cyanohydrins and 2-butanone which is unstable. Fermentation has greater effect on the cyanide value by reducing it to a minimal extent. Production of cyanogenic compound is caused by disruption of structural integrity of plant cells during peeling of cassava tuber, thus, allowing the cyanogenic glycosides from vacuole to come in contact with the enzyme linamarase on the cells wall [7]. Cyanide is very poisonous because it binds cytochrome oxidase and stops its action in respiration, which is a key energy conversion process in the body. The lethal dose for an adult depends on body weight and is between 30 and $110 \mathrm{mg}$ of hydrogen cyanide. Sometimes persons eating a cassava meal exceed these limits and death occurs due to cyanide poisoning. Smaller (non-fatal) amounts of cyanide cause acute intoxication with symptoms of dizziness, headache, stomach pains, vomiting and diarrhea [13].

\section{Chemical analysis of gari during storage}

pH of gari during storage: The $\mathrm{pH}$ of all the samples was discovered to also be decreasing gradually during the storage period from the first week till the last week. The gradual decrease in $\mathrm{pH}$ obtained in all samples during the study might be attributed to the production of acidic metabolites by microorganisms during growth and proliferation [8]. The final $\mathrm{pH}$ of the gari was above the recommended $\mathrm{pH}$ (3.9-4.3) [1]. High $\mathrm{pH}$ is rather undesirable in gari as it might predispose the product to bacterial spoilage.

\section{Titratable acidity of stored gari samples}

The titratable acidity of all the samples within the storage period ranged between 0.0010 and $0.001 \mathrm{mg} / \mathrm{g}$ lactic acid and the details of the analysis. Titratable acidity increased in response to increase in acidity. Titratable acidity of the gari was significantly affected by the fermentation days [3]. 


\section{Conclusion}

The study explored the potentials of substituting breadfruit into cassava to obtain gari analogue. Cyanide value of the coprocessed gari was lower comparable to $100 \%$ cassava gari. $\mathrm{pH}$ value of the gari increased with decrease in titratable acidity. Storage did not produce any appreciable changes in its physicchemical properties for the period of six weeks. Co-fermentation

\section{References}

1 Achinewhu SC (1994) Indigenous fermented foods of Nigeria. Public lecture delivered at the Rivers State University of Science and Technology, Port Harcourt, Nigeria 17.

2 Achinewhu SC, Barber LI, ljeoma IO (1998) Physicochemical properties and garification of selected cassava cultivars in River State, Nigeria. Plant food Human Nutrition 52: 133-140.

3 Achinewhu SC, Owuamanam Cl (2001) Garification of five improved cassava cultivars, physicochemical and sensory properties of gari yield. African Journal of Root Tuber Crops 4: 18-21.

4 Akindahunsi AA, Oboh G, Oshodi AA (1999) Effect of ferrmenting cassaava witth Rhizopus oryzae on the chemical composition of its flour and gari. La Rivista Itaaliaana Delle Sostanze.

5 Akingbala J, Oyewole OB, Uzo-Peters PI, Karim RO, Baccus-Taylor GSH (2005) Evaluating stored cassava quality in gari production. Journal of Food Agriculture and Environment 3: 75-80.

6 Akinrele IA, Cook AS, Holgate RA (1962) The manufacture of gari from Cassava in Nigeria.Pages 633-644 in Proceedings, First International Congress on Food Technology, London.

7 Akinyosoye FA, Olowoyo OO, Adetuyi FC (2001) Microorganisms associated with some cassava (Manihot esculenta crantz) products. Journal of Research and ReviewIn: Sciences 2: 10-14.

8 Amadi JE, Adebola MO (2008) Effect of moisture content and storage conditions on the storability of gari. African Journal of Biotechnology 7: 4591-4594.

9 Amusa NA, Kehinde IA, Ashaye OA (2002) Bio-deterioration of breadfruit (Artocarpus commun) in storage and its effect on the nutrient composition. African Journal of Biotechnology 1: 57-60.

10 AOAC (2005) Official Methods of Ananlysis International ( $18^{\text {th }}$ edn.), Association of Official Analytical Chemist, USA

11 Adeniran HA, Ajifolokun OM (2015) Microbiological studies and sensory evaluation of breadfruit and cassava co-fermented into gari analogue. Nigerian Food Journal. of cassava and breadfruit in the production of gari analogue is an effective way of obtaining gari products of extremely low level of hydrogen cyanide. Thus, this product is considered a safe and convenient functional food for consumption in African countries and other countries where gari is consumed so as to reduce malnutrition and food poisoning as well as promoting utilization of breadfruit.

12 Bokanga M (1995) Biotechnology and cassava processing in Africa. Food Technology 49: 86-90.

13 CCDN (2006) Cassava Cyanide Diseases Network (CCCDN).

14 Cock JH (1985) Cassava: New Potential for a Neglected Crop. Westviev press, Boulder, Colorado, USA, pp: 15-17.

15 Harrigan WF (1998) Laboratory Methods in Food Dairy Microbiology. Academic press San, Diego, CA.

16 Harrigan WF, McCance ME (1998) Laboratory Methods in Food Dairy Microbiology. Academic press, New York.

17 Ihekoronye Al, Ngoddy P (1985) Integrated food science and technology for the tropics ( $1^{\text {st }}$ edn) MacMillian publishers pp: 261 291.

18 ljabadeniyi AO, Omoya FO (2006) Safety of small-scale food fermentations in developing Countries. IUFoST 13t World congress of Food Science and technology 'Food is Life'. Nantess, France pp: 1833-1845.

19 Jay (1986) Isolation and characterization of Bacteriocin producing Lactobacillus sp from traditional fermented foods. Journal of Environment, Agricultural and Food Chemistry.

20 Ngaba RR, Lee JS (1979) Cassava fermentation. Journal of Food Science 44: 1570-1571.

21 Oboh G, Akindahunsi AA, Oshodi AA (2002) Nutrients and antinutrients content of Aspergillus niger fermented cassava products (flour and gari). Journal of Food Composit Analysis 15: 617-622.

22 Oboh G, Akindahunsi AA (2003) Biochemical changes in cassava products (flour and gari) subjected to Saccharomyces cerevisae solid media fermentation. Food Chemistry 82: 599-602.

23 Rosling H (1988) Cassava toxicity and food security: a review of health effects of cyanide exposure from cassava and of ways to prevent these effects. A report for UNICEF African household food security programme ( $2^{\text {nd }}$ edn. $)$, Tryck Kontakf, Uppsala Sweden.

24 Ray RC, Ward O (2006) Post-harvest microbial biotechnology of tropical root and tuber crops. In; Microbial Biotechnology in Horticulture, Ray RC, Ward O editors. pp: 349-356. 